\title{
Child custody issues and co-occurrence of intimate partner violence and child maltreatment: controversies and points of agreement amongst practitioners
}

\author{
Geneviève Lessard $* \dagger$, Catherine Flynn‡, Pierre Turcotte§, Dominique DamantII, \\ Jean-François Vézina**, Marie-France Godin††, France Paradisłł \\ Yennelys AlcedoIIII, Lorraine Juneau***, Linda Rock $+\dagger \dagger$ and Simon Rondeau-Cantin $+\$$ \\ *Co-director, Interdisciplinary Research Centre on Family Violence and Violence Against Women (CRI-VIFF), \\ $\nmid$ Professor, ‡Graduate Student, §Professor, School of Social Work, Laval University, đIProfessor, School of Social Work, \\ University of Montreal, **Director, Groupe d'aide aux personnes impulsives (organization helping violent partners), \\ $\dagger$ †irector, Maison de la famille D.V.S. (organization offering supervised access right), $\$$ \$Preventive Medicine Doctor, \\ Regional Direction of Québec City Public Health, §§Social Worker, Centre de sante et de services sociaux de la \\ Vieille-Capitale (local community service center), IIIPractitioner, Maison pour Femmes Immigrantes (shelter for \\ immigrant women/mothers and their children), ***Practitioner, Centre jeunesse de Quebec - Institut universitaire \\ (child protection services), ††Practitioner, Centre d'amitié Autochtone de Quebec (aboriginal friendship centre), \\ $\$$ \$ $\$$ Graduate Student, School of Social Work, Laval University, Québec, Canada
}

Correspondence:

Geneviève Lessard,

École de service social,

Université Laval,

Pavillon Charles-De-Koninck,

local 6417,

1030, Avenue des

Sciences-Humaines,

Québec (Québec) G1V 0A6,

Canada

E-mail:

genevieve.lessard@svs.ulaval.ca

Keywords: child abuse (neglect), child care policy and practice, divorce (contact issues), domestic violence, research in practice

Accepted for publication: April 2010

\begin{abstract}
The situation of families undergoing separation in a context of co-occurrence of intimate partner violence (IPV) and child maltreatment raises certain issues related to child custody. The results presented in this paper were collected and analysed within the framework of a qualitative study aiming to identify the principal points of agreement and the main controversies amongst practitioners in several different types of organizations. Focus groups were held with a total of 43 practitioners from six different settings concerned with child custody in cases of co-occurrence of IPV and child maltreatment. Although they agreed on the importance of ensuring the safety of victims of violence, their views diverged on three points: (1) the importance of preserving the father-child relationship; (2) collaboration between voluntary organizations and semi-voluntary or legal agencies; and (3) consideration of cultural differences.
\end{abstract}

\section{INTRODUCTION}

In recent decades, the rising divorce rate, diversification of family configurations and influence of fathers' rights groups have led to changes in child custody policies in many Western countries (Rosen

Groupe d'aide aux personnes impulsives is an organization helping violent partners. Maison de la famille D.V.S. is an organization offering supervised access right. et al. 2009). The courts and professionals alike increasingly favour joint custody, as it allows children to maintain contact and a continuous relationship with both parents (Duchesne 2006; Saint-Jacques \& Drapeau 2008). In Québec in 2003, 29\% of divorced parents had joint custody arrangements, a huge jump from $11 \%$ in 1995 (Duchesne 2006). In the USA, joint custody was legalized in all states in the early 1990s. To date, 37 states consider that this should be the first option (Levy 2007). But for families undergoing separation in a context of intimate partner 
violence (IPV), other issues should be also closely examined (Lapierre et al. 2004; Harrison 2008). This paper aims to address these concerns from the perspectives of practitioners in several different settings. We briefly review the literature on the subject before describing our method and findings. We end by suggesting avenues for further research in order to expand our knowledge and improve the services offered to families struggling with IPV and child maltreatment.

\section{CO-OCCURRENCE OF IPV AND CHILD MALTREATMENT}

In this paper, co-occurrence refers to situations in which IPV and child maltreatment coexist in the same family. Numerous studies (Appel \& Holden 1998; Lavergne et al. 2003; Margolin et al. 2003; Finkelhor et al. 2005) have shown that children are often simultaneously exposed to more than one form of violence, especially IPV and direct physical abuse. The median rate of co-occurrence is $40 \%$ in clinical populations, according to a meta-analysis by Appel and Holden (1998). In addition, some children are victims of assault at school, witness the abuse of a sibling or a friend or are victims of crime (Finkelhor et al. 2005). Because IPV and child maltreatment are often approached as two distinct problems, both in the academic literature and in professional practice, many authors stress the importance of improving collaboration between resources concerned so as to provide integrated and consistent assistance to families affected by co-occurrence (Findlater \& Kelly 1999; Schechter \& Edleson 1999; Beeman \& Edleson 2000).

\section{PRINCIPAL CHILD CUSTODY ISSUES IN CASES OF CO-OCCURRENCE}

The safety of maltreated children and victimized parents is a major concern in cases of co-occurrence. When parents separate, the level of violence in the family may remain the same or even escalate (Jaffe et al. 2005; Harrison 2008). In fact, the risk of lethal violence is particularly high in the first few months after separation (Bureau of Justice Statistics 2007; Campbell et al. 2007). Physical violence against an intimate partner before separation often becomes psychological violence after separation (Rinfret-Raynor et al. 2008). The ex-partner then uses his contacts with the children to control, harass or intimidate their mother. For example, he may not respect agreements concerning access rights, threaten the mother with loss of custody if she does not go along with his demands or use the notebook intended for the exchange of information on the children to write messages denigrating her parenting (Rinfret-Raynor et al. 2008). Other studies also show how violent partners may use contact with the children or the legal custody proceedings to control their former partners (Radford et al. 1997; Scott et al. 2002, cited in Jaffe et al. 2005; Harrison 2008). Because IPV is still an issue after separation, it is essential to remain vigilant to ensure that the forms of custody and legal proceedings do not thwart efforts to keep the mother and children safe. Joint custody is not appropriate when there are major conflicts between the partners or when the dynamics of violence continue after separation (Lapierre et al. 2004). When IPV is involved, joint custody is more often requested by fathers; mothers seem to have difficulty opposing their former partners' requests, out of a fear that judges may seem them as hostile, uncooperative and bad mothers (Radford et al. 1997; Côté 2006).

Another important concern is the risk that mothers may be revictimized by practitioners. Sometimes mothers who were victims of violence are blamed for failing to protect their children (Beeman et al. 1999), and this is used against them in custody decisions (Strega et al. 2008).

Finally, it is worth noting that maintaining contact after separation with abusive fathers can have positive effects on children. Stover et al. (2003) have found that children display fewer internalized behavioural problems, including anxiety and depression, when they have weekly contact with their fathers. Nonetheless, children of very violent fathers display externalized problems, regardless of the number of contacts with him after separation. Stover et al. (2003) therefore say that practitioners must consider the child's attachment to the father and seek a way to adapt the relationship and father-child contacts, while ensuring that the child and mother remain safe. This is a crucial point, as the vast majority of violent fathers continue to have access to their children (Kernic et al. 2005; Strega et al. 2008). To preserve the father-child relationship while taking the victims' safety into account, a number of Canadian provinces and American states favour supervised contacts (Kernic et al. 2005; Tutty 2007), yet Tutty found that those working in supervised visitation and exchange centres need more specialized training in the dynamics of IPV.

The child custody issues briefly discussed above highlight the challenges faced by psychosocial practitioners concerned with IPV and child maltreatment. 
Our study focuses on the viewpoints of these practitioners. This research is important, because the existing literature does not provide a deep understanding of their thoughts on child custody issues in cases of co-occurrence.

\section{METHOD}

The results presented here were obtained by means of a qualitative approach aiming to identify the main child custody controversies amongst psychosocial practitioners working in different settings concerned with the co-occurrence of IPV and child maltreatment. These types of organizations, all in Québec City, are identified by the following abbreviations: a local community services centre (LCSC), child protection services (CPS), shelters for abused women and their children (SAWCs), an organization helping violent partners (OVP), services for supervised access rights (SSARs) and resources for First Nations (RFN).

\section{Purposive sampling strategy}

A coordinating committee composed of researchers, graduate students and key informants representing each of the six types of organizations was established. The key informants helped identify participants who should be encountered in order to cover diverse viewpoints, taking into account the specific roles of practitioners in their organizations. The sampling strategy also took into account the fact that some organizations serve the entire target area, while other services are provided by a number of different organizations, determined either by geographic location or the nature of the services offered. All the practitioners interviewed volunteered to take part and received no financial compensation. There were 43 in the final sample. The sample size was determined using the principle of empirical saturation of analytical categories (Deslauriers 1991).

\section{Focus groups}

Participants were interviewed in seven focus groups (Krueger 1994), one for each type of organization, with a second group for the RFNs. According to the coordinating committee member representing this area of practice, this was necessary to take into account the two very distinct realities of aboriginal families living in the urban environment and those living on reserves. Focus groups were run by the lead researcher, assisted by the key informant from each organizational context. The main questions asked were as follows: How do you see situations of co-occurrence of IPV and child maltreatment, and issues related to child custody in those situations? What do you think are the best strategies to help such families dealing with child custody issues? Which factors (facilitators and obstacles) influence your practice in such situations?

\section{Analysis}

With the explicit written consent of the participants, interviews were taped and transcribed in their entirety. Then the data were analysed with N-Vivo software (produced by QSR International, Cambridge, MA, USA), using thematic content analysis (Creswell 1998), first vertically, by categories of analysis, then horizontally, comparing viewpoints by type of organization, so as to identify controversies amongst different groups of practitioners. To ensure the validity of the analysis, each interview's coding was doublechecked to determine inter-judge agreement. The preliminary results were then presented and discussed with the participants. In this way, the analyses were validated and completed, particularly in terms of interpretation of results. The study was also approved by the ethics boards concerned.

\section{RESULTS}

The principal point of agreement emerging from the analyses is that all the groups share a major concern with the safety of the victims of violence. All the organizations named children's safety as a crucial factor in custody decisions in situations of co-occurrence; a number also stressed the importance of ensuring the safety of the abused parent.

Three main controversies were identified. The first concerns the importance of working to improve the father's parenting skills so he can maintain a relationship with his child. The second has to do with the challenges involved in forming partnerships amongst volunteer, semi-volunteer and legal agencies. Finally, the perspectives of practitioners also diverge on the consideration given to cultural differences in dealing with cases of co-occurrence.

\section{Maintaining the father-child relationship}

Practitioners working more directly with violent men (OVP and SSARs) were more open to maintaining the 
father-child relationship. On the other hand, practitioners from SAWCs and CPS found it difficult to do so while at the same time keeping the victims safe. Practitioners encountered at the LCSC were divided on the issue; some were more inclined than others to favour maintaining the father-child relationship. Finally, the RFN practitioners explained that this controversy does not affect them, given that it is practically impossible to prevent or even control contacts between fathers and children in First Nations communities. The involvement of the extended family and physical proximity within the community combine to give the fathers easy access to their children. Differences in organizational contexts, as well as in perceptions of the dynamics of family violence, help to explain the positions on the first controversy.

\section{Influence of organizational missions}

The position of practitioners consulted on maintaining contact between fathers and children seems consistent with the missions of each type of organization. The groups of practitioners principally responsible for the safety of victims (CPS and SAWCs) were less favourable to maintaining the father-child relationship, because they deemed this strategy to be counter to their efforts to protect the victims. The mission of SSARs, on the other hand, is to enforce court orders allowing violent parents to meet their children in a safe and supervised environment. Moreover, their mission consists of 'maintaining the emotional bond between parent and child, but never to the detriment of the child's development.' It therefore seems logical to believe that their decision to foster the father-child relationship and to define this relationship as a right may be influenced by their organization's mission.

\section{Differential access to family members}

The positions of the practitioners interviewed also seem to be influenced by the family members with whom they work, which gives them a different understanding of the family dynamics of co-occurrence. OVP practitioners, for instance, have a special insight into violent men, who are said to be difficult to reach through other organizations, such as the LCSC. The OVP practitioners believe that such men are capable of introspection and can be sensitized to the impact of their violent behaviour on their children. They explained that some men fail to recognize the violent character of their behaviour in order to protect them- selves from the discrepancy between their own selfperception as non-violent, their idea of an abusive spouse as sadistic and evil and the violent nature of their acts. They said that some violent men see in their behaviour a reflection of how own father's treated them. This confrontation between their experience as abused children and their desire not to have their children experience the same thing may be painful. In the opinion of the OVP practitioners, such an awareness supports the idea that violent men are capable of introspection, that they can experience guilt and that they are aware of the discrepancy between their values and their actions.

We often hear, 'I realized that I was acting like my father [ . . ] . I hate my father, but I realize that I'm becoming just like him, although it's the last thing on earth that I want to do.' (OVP)

Sometimes I think they don't talk about it because they may feel guilty. They don't want to show that they're violent in all spheres of their lives. [ . . . ] According to their values, touching a child or being violent towards a child, isn't right. There is denial sometimes, but it's, well, a kind of sensitivity, or a defence mechanism. (OVP)

The SSARs practitioners were also favourable to maintaining father-child contacts, as they usually witness father-child interactions during supervised visits. On the other hand, practitioners from the SAWCs have special access to the discourse and experience of the victims of violence because they work daily with women and children. Their experiences make it difficult for them to favour maintaining the father-child relationship, because a number of their client's partners seem to feel little responsibility and show scant awareness of the impact of their violence on their partners and children.

$\mathrm{He}$ [the father] is not sensitized to his violence towards his family. He totally abdicates responsibility. (SAWCs).

Because of issues related to the victims' safety, the practitioners encountered at CPS and some at the LCSC said that it is difficult for them to work with both aggressors and victims at the same time. As a result, in situations of co-occurrence, they work more with mothers. Moreover, LCSC practitioners pointed out that requests for assistance generally come from mothers, and it is more difficult for them to reach fathers and interest them in improving their parenting skills.

While some organizations would like to reach violent men, the CPS practitioners, who have the legal obligation to contact the father, highlighted the challenges of doing so. Working with the entire family 
allows for a more comprehensive view of the family dynamics, and thus a more accurate assessment of child custody issues. However, the CPS practitioners also expressed the fear that confronting the violent partner could, in some cases, exacerbate his violent conduct, thus putting the children and their mother at risk. Furthermore, in cases of co-occurrence, strategies such as family interviews, though generally useful, prove to be more problematic and may even endanger the mother and children, because they heighten the risk that the practitioner could be used, or even controlled, by the violent man. The SSARs practitioners mention the danger of being drawn into the dynamics of family violence through their contact with both parents during the custody exchange.

Because one of the dangers when you work with the violent partner [ . . ] is that if you confront him and then he loses face, or he loses power, it's the mother or the children who will suffer the consequences. (CPS)

One of the things I found difficult was I felt like I was being used by the father. (CPS)

You have to be very careful to not identify with the victim. You know the pattern of the victim and her torturer. As a practitioner, you run the risk of taking sides. (SSARs)

While working with both parents raises its share of difficulties, seeing the perspective of only one of the family members may also complicate analysis of issues related to maintenance of the father-child relationship. For example, the OVP practitioners do not have access to the child's viewpoint to assess the emotional bond with the father. Yet this factor seems to be very important in decisions related to maintaining fatherchild contact. Thus, they recognized that they could be biased as a result of having access to just one side of the story and sometimes forgetting the experience of the children or their mother. Nonetheless, this position is not held by everyone within the organization. Practitioners from the SAWCs also expressed some dissatisfaction with working only with the mother and child without the father also being able to receive help in modifying his violent behaviour.

We are biased $[\ldots]$. Working with only one aspect, at a certain point, you forget all the rest, you forget to consider the experience of the mothers in all this, or you don't take the children into account as much. (OVP)

I find it difficult to work with the women, with the children. We explain the consequences of the violence for her, for her child, and the family dynamics. It goes to court - joint custody or every second weekend. And nothing is being done with the father. That means that we're practically operating in a vacuum. (SAWCs)

\section{View of the dynamics of violence}

The way the practitioners perceive the dynamics of co-occurrence may also influence their position on maintaining father-child contact. One point of divergence amongst them concerns the direction of family violence. While practitioners from the CPS, RFN, OVP and SAWCs stress that in the vast majority of cases the man is the abuser and the woman is the victim, some practitioners from the LCSC and SSARs believe that IPV within these families can be a twoway street.

[...] Well, it's often the mothers who are abused by their partners. (CPS)

It's always the men who are the aggressors. (SAWCs)

It could be the man $[\ldots]$ who is very violent towards his partner. [ ...] But we also see that in other situations, the mother is capable $[\ldots]$ of violence against her partner. (LCSC)

Both male and female partners have been victims of violence, I believe. (SSARs)

\section{Co-occurrence: a favourable context for parental alienation?}

Practitioners' concern with the possibility of parental alienation may also be a factor to consider in their position on maintaining father-child contact. They said that parental alienation can be seen when a child struggles with conflicting loyalty between the parents or when one of them uses the child to try to dominate the other. SAWCs practitioners reported that their clients sometimes complain that their ex-partner is trying to alienate their child. They find it difficult to encourage maintaining the father-child connection in this situation. The RFN practitioners, as well as some of those from the LCSC, also consider that fathers may use their children to get to or harm the mother.

The violent man used the children a great deal to take revenge on his partner who had left him. It is an incredible, blatant form of parental alienation. (LCSC)

The father often intimidates the child, uses the child as a go-between, frightens the child: If you don't do such-andsuch, I'll hurt your mother. (RFN)

But SSARs practitioners believe that both parents may engage in alienation tactics, and they believe it is possible to disrupt this dynamic, at least during supervised visits. From their perspective, their service protects children by limiting alienating behaviour during supervised contacts, because they take place in a neutral and safe environment. 


\section{Difficulties with organizational collaboration}

Our findings suggest the difficulties of collaboration amongst the principal actors in the voluntary, semivoluntary and legal sectors. The semi-voluntary sector includes community organizations with a mandate to enforce Youth Court or Superior Court orders concerning supervised access. The participants mentioned factors that adversely affect relations with their organizational partners. First, relations between organizations of unequal power seem to generate considerable frustration. Second, the lack of awareness of what others do and interference in their spheres of jurisdiction also hinder efforts at collaboration.

\section{Power imbalance}

Most of the practitioners interviewed say that it is difficult to work with CPS because of the unequal sharing of information. Because of the legal powers of investigation of CPS, practitioners in voluntary and semi-voluntary organizations said that information circulates almost exclusively towards CPS and that they are very ill-informed about CPS dealings with their clients. The participants from the LCSC, SAWCs and RFN also stressed that parents tend to associate their organizations with CPS, and so distrust the services offered and the practitioners themselves.

You get the impression information moves [in only one direction]. That doesn't necessarily make you feel like saying any more than you have to. (OVP)

What bothered me [in this situation] is that she [the client] sort of pulled back from me a little because she associated me closely with the CPS. (LCSC)

\section{Lack of information about other organizations}

Lack of information about what the other organizations do is another obstacle to collaboration. Practitioners from SSARs, CPS and SAWCs said that they sometimes receive requests outside of their usual framework of practice. Some organizations pointed out that false beliefs circulate about their services. For example, OVP practitioners explained that some organizational partners, particularly from CPS and the legal milieu, wrongly believe that the risk for the woman and her children is eliminated when the violent partner starts to get help. For their part, SWACs practitioners said that some organizational partners harbour prejudices against shelters and advise their clients not to go there.
Sometimes I have to explain my work, because I don't have the same tasks and I have a different sort of legal framework than other partners. (CPS)

I think that there are still situations where we are taken as a guarantee that once they cross our threshold, they're out of danger. (OVP)

I even have women [ ... ] who don't want to come here with their children because of what they've been advised - that shelters will upset the children. (SAWCs)

Interference in organizational partners' work was also identified as a possible hindrance to the process of collaboration amongst the groups, because it indicates a lack of confidence in a particular organization.

Sometimes social workers want to come along, but we say no, [ . . ] we can manage. I have people to take care of it, trained for it, so they don't need to be here. They should trust us. (SSARs)

\section{Consideration of cultural differences when helping immigrant and first nations families}

Practitioners from SAWCs and CPS stressed the difficulties of working with immigrant families of different ethnic groups who have diverse cultural values. Their challenge is to promote non-violent behaviour, while at the same time respecting family customs.

We don't accept any form of violence in the shelter, [but] what can make things a bit more difficult is that we have to respect their culture, too. (SAWCs)

The cultural issue was also raised by RFN practitioners, with respect to the difficulty their clients have in obtaining appropriate assistance that takes cultural differences into account. They stress that family violence within First Nations communities arose in a different context than in of the rest of the Québec population, and that a lack of awareness of this reality or a lack of openness could lead to misperceptions of the issue amongst practitioners from non-aboriginal organizations. According to practitioners from RFN, this controversy is also attributable to cultural differences in child-rearing practices. In the past, the relationship between fathers and mothers in First Nations communities was egalitarian. Parents were considered to have complementary roles within the family and in bringing up children. The advent of Catholicism, and especially the establishment of residential schools, overturned this concept of family life by imposing non-Native values and relegating women to an inferior position. According to the participants, these historic events led to the emergence of family violence. They added that the concept of family and extended family within First Nations communities has contributed to 
the intergenerational transmission of violence. The extended family may exercise a lot of pressure on the mother to accept the abuse and stay with her partner, in order to keep the family together.

It is religion that $[\ldots]$ totally changed their values. [ . . ] There has been intergenerational transmission of family violence, but also [ . . . ] pressure has been exerted. (RFN)

The RFN practitioners explained that their clients sometimes have trouble with CPS, as some culturally determined parenting behaviours and attitudes are deemed inappropriate. They therefore suggested that CPS need to adapt and define social problems within an aboriginal cultural framework.

We've always had trouble getting CPS practitioners to accept the differences in how our families live, how we raise our children, our degree of tolerance, but they're intransigent. (RFN)

\section{DISCUSSION}

The first controversy hinges on divergences amongst practitioners on the issue of the father-child relationship. The positions of the groups concerned appear to be influenced by the family members they serve, which shows the importance of bringing together the different perspectives and working in concert, in order to ultimately arrive at a broader and more thorough vision of child custody issues in a situation of co-occurrence. It also emerged that practitioners from the organizations least favourable to maintaining contact between father and child in such cases perceive the mother and children as the main victims. However, OVP practitioners, who are more favourable to maintaining contact, also perceive the mothers and children as the principal victims. Perhaps their special contact with men and their familiarity with their experiences allow them to note certain potential or actual parenting skills that will enable them to embark on a process of change. This may be why these practitioners are generally favourable to maintaining the father-child relationship, as long as it does not compromise the safety of the victims. The divergences among practitioners from the LCSC on the question of maintaining father-child contact may be explained by the fact that their organization offers front-line services to families with diverse issues.

An analysis of the literature in the field reveals the same controversy. Indeed, some authors (Fox et al. 2001; Stover et al. 2003) stress that, as long as the victims' safety is assured, the father-child relationship remains important, even in the context of co- occurring violence, because encouraging violent men to connect with their role as fathers could be the prelude to recognizing the impact of violence on family members and a condition contributing to engaging in a process of change (Fox et al. 2001). Others (Lapierre et al. 2004; Jaffe et al. 2005) consider that when the parents have a very conflictual relationship, maintaining contact between father and child through joint custody, for example - may be more harmful to the child's adjustment and expose the child to inappropriate relationship models. Thus, as suggested by Edleson et al. (2003), it seems vital to pursue a rigorous assessment of the programmes offered to fathers and children. One such programme has been developed by Groves et al. (2007), who first experimented with working on improving the motherchild relationship. The authors now hope to extend the programme to fathers, especially because the mothers were favourable to the idea. Other studies show that although many mothers who are victims of IPV see the value of maintaining father-child contact, it is harmful for the child and the women when violence continues after separation (Radford et al. 1997; Harrison 2008; Rinfret-Raynor et al. 2008).

According to some of the study participants, violent men are sometimes unaware of the impact of their violence on victims. It is therefore important that a feminist approach be taken in working with these fathers. An important objective would be to sensitize them to the need to cooperate with the mother and maintain a respectful, non-violent relationship with her (Edleson et al. 2003). Moreover, because mothers are usually less likely than fathers to abdicate their parental responsibilities after separation (Strega et al. 2008), it is important to consider the emotional bond between father and child and the significance that the man attributes to fatherhood. It is crucial, as recommended by Bourassa et al. (2008), to do further research to document the father-child relationship and fathering in the context of co-occurring violence. While such research poses a number of challenges, solutions may still be possible. For example, custody arrangements and supervised visits could be better adapted to the problem of IPV (Tutty 2007; RinfretRaynor et al. 2008).

Considerable research has already acknowledged the difficulties of coordinating various organizations and resources in the fields of child protection and IPV (Beeman et al. 1999; Findlater \& Kelly 1999; Beeman \& Edleson 2000). Also, some authors (Featherstone \& Peckover 2007; Strega et al. 2008) have lamented the invisibility of fathers in CPS and the fact that services 
focus almost exclusively on the mother. On the other hand, as our results show, it is not easy for CPS practitioners to involve the father in the process without increasing the risk of revictimizing the woman and children. Harmonization of practices amongst the various organizational partners would thus seem to be the best strategy to offer appropriate and continuous assistance that takes into account issues of victim safety. Beeman and Edleson (2000) present some innovative programmes involving collaboration amongst different organizations concerned with the issue.

It appears that cultural differences are worth noting and considering in work with aboriginal and immigrant parents in a context of co-occurrence. Enhanced knowledge of the cultural realities of the families concerned would help organizations provide services better suited to their needs (Bourassa et al. 2008) and more accurately identify child custody issues. Our results highlight the importance of conducting further research to develop knowledge on the influence of cultural values and norms on the dynamics of family violence, so as to better incorporate this dimension into assistance offered to families affected by IPV and child maltreatment.

In short, the analysis and discussion of each controversy identified in this study points to the need for a holistic approach to the problem and solutions. The points of view and expertise of practitioners from a variety of organizations concerned with co-occurrence of IPV and child maltreatment need to be shared so as to develop helping strategies grounded in a deeper understanding of child custody issues.

\section{CONCLUSION}

In this paper we argue that although joint custody is perceived by courts and professionals as a good way to allow children to preserve contact and a continuous relationship with both parents (Duchesne 2006; Levy 2007; Saint-Jacques \& Drapeau 2008), when separation occurs in a context of IPV and child maltreatment, the situation is much more complex and raises issues related to the safety of abused children and parents (Lapierre et al. 2004; Jaffe et al. 2005; Harrison 2008). Practitioners helping these families do not all share the same point of view on child custody issues in cases of co-occurrence of IPV and child maltreatment. Our study provides a better understanding of practitioners' thoughts on child custody issues in such cases. We have identified three main controversies and points of agreement amongst practitioners working in six different types of organizations.

Because of the study design, our findings should obviously not be generalized to all practitioners in the field. However, the description of the context in which the study was done and the analytical methods employed allow a thorough assessment of its transferability - this criterion was proposed by Lincoln and Guba (1985) to assess qualitative research - of these results to other contexts. In addition, the coding of the empirical data collected was double-checked through inter-judge agreement and interpretation of the results was validated through discussion with the practitioners concerned; these strategies strengthen the credibility of the study (Lincoln \& Guba 1985). Nonetheless, in our view, other researchers employing diverse quantitative and qualitative methods should test our results. The complexity of challenges faced by practitioners concerned by the co-occurrence of IPV and child maltreatment demands further development of knowledge and practice in this field.

\section{ACKNOWLEDGEMENTS}

We would like to thank the Fonds québécois de la recherche sur la société et la culture (Quebec Fund for Research on Society and Culture) and the Centre interdisciplinaire de recherche sur fa violence familiale et la violence faile aux femmes (Centre for Interdisciplinary Research on Family Violence and Violence Against Women) for their financial support in the production of this research.

\section{REFERENCES}

Appel, A.E. \& Holden, G.W. (1998) The co-occurrence of spouse and physical child abuse: a review and appraisal. fournal of Family Psychology, 12, 578-599.

Beeman, S.K. \& Edleson, J.L. (2000) Collaborating on family safety: challenges for children's and women's advocates. Fournal of Aggression, Maltreatment and Trauma, 3, 345-358.

Beeman, S.K., Hagemeister, A.K. \& Edleson, J.L. (1999) Child protection and battered women's services: from conflict to collaboration. Child Maltreatment, 4, 116-126.

Bourassa, C., Robinson, J., Lessard, G., Turcotte, P., Lavergne, C., Damant, D. et al. (2008) La maternité et la paternité en contexte de violence conjugale. [Motherhood and fatherhood in a context of domestic violence]. In: Visages multiples de la parentalité (eds C. Parent, S. Drapeau, M. Brousseau \& E. Pouliot), pp. 321-360. Presses de l’Université du Québec, Québec.

Bureau of Justice Statistics (2007) Intimate partner violence in the U.S. Available at: http://bsj.ojp.usda.gov/content/pub/pdf/ ipvus.pdf (accessed 25 November 2009). 
Campbell, J.C., Glass, N., Sharps, P.W., Laughon, K. \& Bloom, T. (2007) Intimate partner homicide: review and implications of research and policy. Trauma, Violence $\mathcal{E}$ Abuse, 8, 246269.

Côté, D. (2006) Une modalité consensuelle de résolution de conflits peut-elle avoir des effets pervers? Garde partagée et violence des ex-conjoints. [Can consensual conflict resolutions have perverse effects? Foint custody and ex-partner violence]. Association francophone pour le savoir (ACFAS), May 16, Montréal, Québec, Canada.

Creswell, J.W. (1998) Data analysis and representation. In: Qualitative Inquiry and Research Design (ed. J.W. Creswell), pp. 139-165. Sage, Thousand Oaks, CA.

Deslauriers, J.-P. (1991) Recherche Qualitative: Guide Pratique. [Qualitative Research: A Practical Guide]. McGraw-Hill, Montréal.

Duchesne, L. (2006) La situation démographique au Québec. Bilan 2006. [The Demographic Situation in Quebec, 2006]. Institut de la statistique du Québec, Québec.

Edleson, J.L., Mbilinyi, L.F. \& Shetty, S. (2003) Parenting in the Context of Domestic Violence. Judicial Council of California, San Francisco, CA.

Featherstone, B. \& Peckover, S. (2007) Letting them get away with it: fathers, domestic violence and child welfare. Critical Social Policy, 27, 181-202.

Findlater, J.E. \& Kelly, S. (1999) Child protective services and domestic violence. The Future of Children, 9, 84-96.

Finkelhor, D., Ormrod, R.K., Turner, H.A. \& Hamby, S.L. (2005) The victimization of children and youth: a comprehensive, national survey. Child Maltreatment, 10, 5-25.

Fox, G.L., Sayers, J. \& Bruce, C. (2001) Beyond bravado: redemption and rehabilitation in the fathering accounts of men who batter. Marriage and Family Review, 32, 137-163.

Groves, B.M., Van Horne, P. \& Lieberman, A.F. (2007) Deciding on fathers' involvement in their children's treatment after domestic violence. In: Parenting by Men Who Batter New Directions for Assessment and Intervention (eds J.L. Edleson \& O.J. Williams), pp. 65-84. Oxford University Press, New York.

Harrison, C. (2008) Implacably hostile or appropriately protective? Women managing child contact in the context of domestic violence. Violence Against Women, 14, 381-405.

Jaffe, P., Lemmon, N. \& Poisson, S. (2005) Child Custody and Domestic Violence: A Call for Safety and Accountability. Sage, Thousand Oaks, CA.

Kernic, M.A., Monary-Ernsdorff, D.J., Koepsell, J.K. \& Holt, V.L. (2005) Children in the crossfire: child custody determinations among couples with a history of intimate partner violence. Violence Against Women, 11, 991-1021.

Krueger, R.A. (1994) Focus Groups: A Practical Guide for Applied Research. Sage Publications, Thousand Oaks, CA.

Lapierre, S., Lessard, G. \& Turcotte, D. (2004) La séparation dans un contexte de violence conjugale: quels sont les défis pour l'intervention auprès des enfants. [Separation in a context of domestic violence: what are the challenges when working with children.]. In: Séparation, monoparentalité et recomposition familiale: bilan d'une réalité complexe et pistes d'actions (eds M.-C. Saint-Jacques, D. Turcotte, S. Drapeau \& R. Cloutier), pp. 195-216. Presses de l'Université Laval, Québec.

Lavergne, C., Chamberland, C., Laporte, L. \& Baraldi, R. (2003) Domestic violence: protecting children by involving fathers and helping mothers. Centres of Excellence for Children's Wellbeing, Information Sheet \#6E.

Levy, D.L. (2007) Some critical issues in custody. American Fournal of Family Law, 21, 57-58.

Lincoln, Y.S. \& Guba, E.G. (1985) Establishing trustworthiness. In: Naturalistic Inquiry (eds E.G. Guba \& Y.S. Lincoln), pp. 289-331. Sage, Beverly Hills, CA.

Margolin, G., Gordis, E.B., Medina, A.M. \& Oliver, P.H. (2003) The co-occurrence of husband-to-wife aggression, family-of-origin aggression, and child abuse potential in a community sample. Fournal of Interpersonal Violence, 18, 413440 .

Radford, L., Hester, M., Humphries, J. \& Woodfield, K.-S. (1997) For the sake of the children: the law, domestic violence and child contact in England. Women's Studies International Forum, 20, 471-482.

Rinfret-Raynor, M., Dubé, M., Drouin, C., Maillé, N. \& Harper, E. (2008) Violence conjugale postséparation en contexte d'exercice des droits d'accès aux enfants. [Post-separation violence in the context of supervised visitation rights]. In: Violences faites aux femmes (eds S. Arcand, D. Damant, S. Gravel \& E. Harper), pp. 185-207. Presses de l'Université du Québec, Québec.

Rosen, L.N., Dragiewicz, M. \& Gibbs, J.C. (2009) Fathers's rights group: demographic Correlates and Impact on Custody Policy. Violence against Women, 30, 513-531.

Saint-Jacques, M.-C. \& Drapeau, S. (2008) Dans quel type de familles grandiront les enfants québécois en 2020? Un examen de la diversité familiale et des défis qui y sont associés. [In which kind of family will Quebec children grow up in 2020? An analysis of family diversity and the associated challenges]. In: La famille à l'horizon 2020 (eds I. Bitaudeau, C. Dumont \& G. Pronovost), pp. 101-143. Presses de l’Université du Québec, Québec.

Schechter, S. \& Edleson, J.L. (1999) Effective Intervention in Domestic Violence and Child Maltreatment Cases: Guidelines for Policy and Practice. Recommendations from the National Council of fuvenile and Family Court Fudges. Family Violence Department, Reno, NV.

Stover, C.S., Van Horn, P., Turner, R., Cooper, B. \& Lieberman, A.F. (2003) The effects of father visitation on preschool-aged witnesses of domestic violence. Fournal of InterpersonalViolence, 18, 1149-1166.

Strega, S., Fleet, C., Brown, L., Dorninelli, L., Callahan, M. \& Walmsley, C. (2008) Connecting father absence and mother blame in child welfare policies and practice. Children and Youth Services Review, 30, 705-716.

Tutty, L. (2007) Supervised Visitation and Exchange Centres for Domestic Violence: An Environmental Scan of Canadian Programs. Third International Conference on Children Exposed to Domestic Violence, May 11, London, Ontario, Canada. 